\title{
Avoidance responses to pure tones in the rat
}

\author{
James H. Dewson, III \\ STANFORD UNIVERSITY SCHOOL OF MEDICINE
}

\begin{abstract}
Shuttle-box avoidance responses to pure tone stimuli at intensities from 0 to $115 \mathrm{db}$ SPL were recorded for two male albino rats. Functions relating response probability to stimulus intensity were approximately linear in form, with the overall level of response being higher at higher stimulus frequencies.

\section{Problem}

Despite several published investigations of the auditory acuity of the rat, behavioral response functions covering a wide range of stimlus intensities are not to be found in the literature, Many studies, moreover, have not specified the auditory stimulus in standard terms of acoustical measurement so that interpretation and/or replication of the results raises certain problems. Previous determinations of auditory thresholds for the rat have involved both classical and instrumental conditioning procedures. Cowles \& Pennington (1943) used conditioned vocalization (squeak) evoked by electric shock, while Jamison (1951) used conditioned depression of heart rate evoked by inhalation of ammonia gas. Gould \& Morgan (1942) employed an instrumental avoidance procedure and, more recently, Gourevitch et al (1960), adapting the Bekesy technique to the operant conditioning situation for rats, have obtained long-term stable measures of auditory threshold at $2000 \mathrm{cps}$.

In the studies cited above, the only results reported are intensity thresholds, i. e., the approximate $50 \%$ response level. It should be recognized that a specification of threshold for a particular frequency tells us little about whether, or in what way, S's behavior is lawfully related to variations in intensity of the auditory stimulus. In addition to threshold data, we would like to know something about the rat's resolving power between intensities at particular frequencies; this aspect of the rat's auditory sensitivity may be inferred from the slope of his frequency-intensity function. The present study offers complete functions for the frequencies $250,500,1000,3000$, and $8000 \mathrm{cps}$, derived from electric-shock avoidance conditioning procedures.

\section{Subjeets}

Two male albino rats, 150 days old at the beginning of training, served as Ss. They were housed in a community cage on an ad lib. diet of water and Purina lab checkers.

\section{Apparatus}

A shuttle box $29 \times 5-1 / 2 \times 17-1 / 2$ in high with a transparent plastic front and a metal grid floor was placed 1 in above a 12 in loudspeaker whose response characteristics were known to be essentially flat from 100 to $10,000 \mathrm{cps}$. The auditory stimuli were led to the loudspeaker from an Allison 21B audiometer (which provides adequate suppression of onset transients) and could be varied in frequency, intensity, and duration. Stimulus intensities in decibels re: 0.0002 dyne $/ \mathrm{cm}^{2}$ (db SPL) were measured relative to the S's average position in the shuttle box when the tone was presented and were specified as the average SPL readings on the C scale of a General Radio 1551-B sound level meter. The shock was 180 v.a.c. dropped across a .25 megohm resistor in series with the grid. Testing was performed in a two-room suite, with the shuttle box and loudspeaker in a sound-treated room, and all programming equipment in an adjacent, acoustically-isolated control room. Ss were observed through a double-pane window.

\section{Procedure}

(a) Pretraining. Each $\mathrm{S}$ was given a pretraining session of 200 trials of avoidance conditioning. The conditional stimuli (CSs) for these trials were tones which randomly varied among those frequencies and intensities which $\mathrm{S}$ would encounter during the testing procedure. $\mathrm{S}$ had $3 \mathrm{sec}$. following the onset of the tone to avoid shock by crossing to the other side of the box. When $\mathrm{S}$ crossed the midline of the shuttle box the CS was terminated. If $\mathrm{S}$ failed to respond within 3 sec., shock was delivered and continued, along with the CS, until $\mathrm{S}$ crossed the midline at which time both the shock and the tone were immediately terminated. Inter-trial intervals varied randomly about a mean of $15 \mathrm{sec}$.

(b) Testing. Following the pretraining sessions, Ss received a series of test sessions, each involving 180-240 trials. In addition, a retraining warm-up period was given prior to each testing session in which the higher intensities of the frequency to be tested were presented unil S responded to 9 of 10 CS presentation; Ss rarely needed more than 20 retraining trials to reach this criterion. Sessions were separated by at least $24 \mathrm{hr}$.; an entire test series required 10 sessions. Stimulus intensities for the single frequency tested in each session were presented at discrete $10 \mathrm{db}$ steps in randomized order; 20 trials were given at each intensity point. This schedule was followed for frequencies of $250,500,1000$, and $3000 \mathrm{cps}$; at $8000 \mathrm{cps}$, CS intensities were held constant over blocks of 20 trials, with the intensity blocks occurring in random order. The entire design was repeated once.

\section{Results and Discussion}

The results are depicted in Fig. 1, which shows percentage avoidance responses at different intensity steps in db SPL. Each point is based upon 80 observations from the two rats. The response measure is clearly sensitive to variations in CS intensity; in general, at the lower intensity levels, response probability increases with stimulus frequency. A striking 


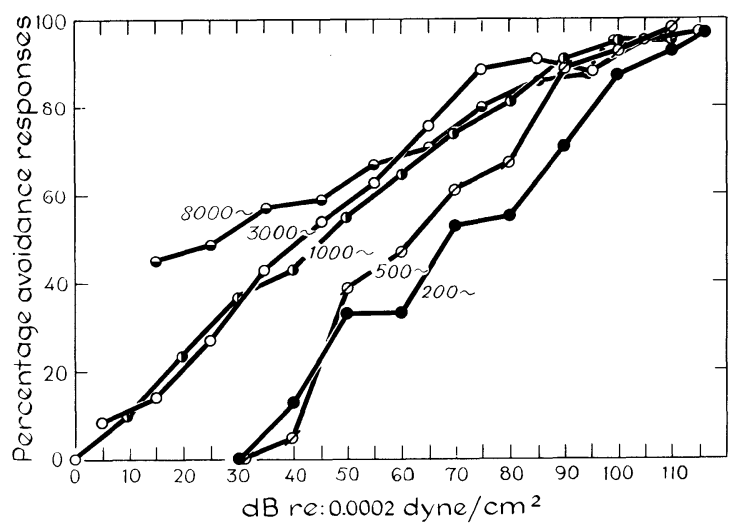

Fig. 1. Average percentage avoidance responses for two rats as a function of stimulus intensity; the parameter of the five curves is frequency in cps. Each point based upon 80 observations.

feature of these functions is their linearity over the range of values studied. This linearity is representative of the functions for each $\mathrm{S}$ and is not a result of data averages. The slope of the function decreases, while the intercept increases with frequency.

The $\mathrm{db}$ level at which the separate frequency curves cross the $50 \%$ response point may be taken for comparison with previously published figures for the rat's auditory thresholds. In this study, the 50\% response points were $67 \mathrm{db}$ at $250 \mathrm{cps}, 63 \mathrm{db}$ at $500 \mathrm{cps}, 46 \mathrm{db}$ at
$1000 \mathrm{cps}, 41 \mathrm{db}$ at $3000 \mathrm{cps}$, and $26 \mathrm{db}$ at $8000 \mathrm{cps}$. The threshold estimate at $500 \mathrm{cps}$ is identical to the value reported by Cowles and Pennington. At $2000 \mathrm{cps}$ threshold vlaues reported previously (Cowles \& Pennington, 1943; Jamison, 1951; Gourevitch et al, 1960) range from 37 to $47 \mathrm{db}$ SPL; the value interpolated from the curves in Fig. $1(44 \mathrm{db}$ ) falls well within this range. At $8000 \mathrm{cps}$, Jamison reported a threshold range from 18-32 db which includes the present estimate of $26 \mathrm{db}$ SPL.

An important consideration in evaluating these threshold estimates is the fact that responses were evoked over an appreciable range of intensities below the $50 \%$ point. These responses must have been evoked by the auditory stimulus since random, inter-trial responding was a negligible factor.

\section{References}

COWLES, J. T., \& PENNINGTON, L. A. An improved conditioning technique for detecting auditory acuity of the rat.J. Psychol., 1943, 15, 41-47.

GOULD, J., \& MORGAN, C. T. Auditory sensitivity in the rat. J. comp. Psychol., 1942, 34, 321-329.

GOUREVITCH, G., HACK, M. H., \& HAWKINS, J. E. JR. Auditory thresholds in the rat measured by an operant technique. Science, $1960,131,1046-1047$.

JAMISON, J. H. Auditory thresholds in the rat. J. comp. physiol. Psychol., 1951, 44, 118-125.

\section{Note}

1. This research was completed during the writer's tenure on a predoctoral fellowship from the Office of Vocational Rehabilitation, and was supported by NIMH Grant M 3849 to Dr. Gordon H. Bower. I acknowledge the advice and assistance of Dr. Bower. 